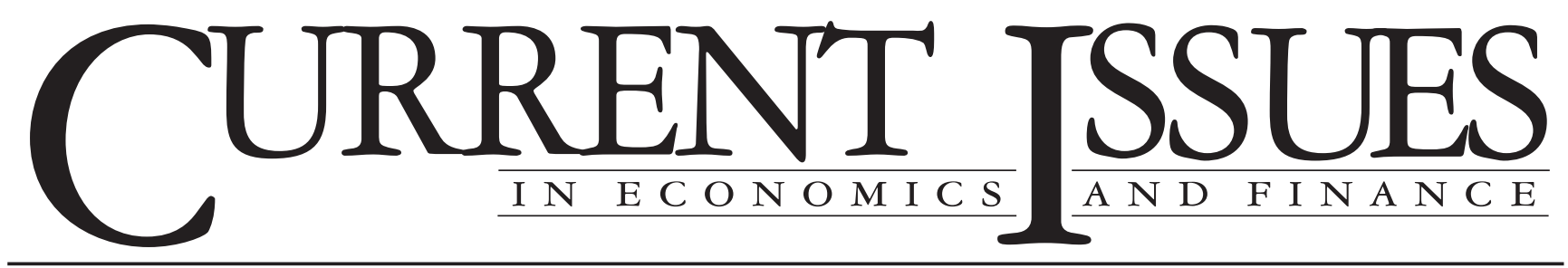

September 1997

Volume 3 Number 11

\title{
Do Rising Labor Costs Trigger Higher Inflation?
}

David A. Brauer

The evidence that developments in compensation growth lead overall CPI inflation has thus far been inconclusive. This study, however, sheds new light on the relationship between labor costs and price inflation. By breaking down compensation and prices into their various components, the author finds that compensation growth in the service-producing segment of the private sector can help predict prices for a specific group of services.

Policymakers have followed with great interest the search for a reliable early indicator of inflation. One measure that has received considerable attention is the changes in hourly compensation-wages and benefits - of workers. On average, compensation represents about two-thirds of the total cost of production, and economic theory suggests that an increase in the rate of compensation growth will lead to accelerating price inflation unless the increase is offset by greater productivity growth or a squeeze on profits.

Throughout the 1990s, both the employment cost index (ECI) - which measures the rate of change in employers' hourly costs of providing wages, salaries, and benefits - and the consumer price index (CPI) the most widely watched inflation measure-have risen at moderate rates relative to the previous decade. More broadly, movements in the two measures, both of which are produced by the U.S. Department of Labor's Bureau of Labor Statistics (BLS), have often mirrored one another. However, the evidence that compensation growth developments lead overall CPI inflation has thus far been inconclusive.

This edition of Current Issues attempts to clarify some of the ambiguity surrounding the links between labor costs and price inflation over the post-1982 period. By breaking down compensation and prices into their various components, this study demonstrates that compensation growth in the service-producing segment of the private sector can help predict prices for a specific group of services and that these prices can in turn help predict movements in goods prices. However, compensation growth among goods producers in the private sector is shown to have little predictive power for goods prices. Overall, these results suggest that by concentrating on compensation developments in private sector services, we can obtain important information about the future path of inflation.

\section{Previous Studies of Labor Costs and Inflation}

Several economists have attempted to sort out statistically the links between compensation and prices, with mixed results. For example, Gordon (1988) finds that for the 1954-87 period, wages and prices are determined by separate processes. More recently, Emery and Chang (1996) show that unit labor costs (compensation growth minus productivity growth) have no forecasting power for CPI inflation during the 1990s. On the one hand, Mehra (1991) and Huh and Trehan (1995) find that although unit labor costs and output prices move in tandem over the long run, prices lead labor costs but not vice versa. On the other hand, Mehra (1993) shows that changes in consumer prices and labor costs help to predict one another. Finally, Lown and Rich (1997) conclude that unit labor costs play a role in predicting inflation over the 1965-96 period. 
In general, all of these results tend to be sensitive to the period of analysis, the exact question asked, and the specific labor cost and price measures used. Significantly, none of the studies uses the ECIthe best measure of labor cost inflation currently available-because the relevant series of the ECI have only been issued since the late 1970 s or early $1980 \mathrm{~s} .{ }^{1}$ Moreover, none of these studies uses a disaggregated approach to examine labor costs or price inflation.

\section{Labor Costs and Price Determination in the Goods and Services Sectors}

Theoretically, a link between compensation and prices could run in either direction. For instance, firms whose compensation costs are rising more rapidly than their productivity growth could at some point be expected to attempt to raise product prices. However, higher price inflation could itself trigger more rapid compensation growth through explicit or implicit contractual arrangements (such as cost-of-living allowances) or through the influence of inflation expectations on the wagesetting process. Consistent with theory, when we first examine the relationship between private sector compensation and prices on an aggregate level, we, like the other researchers, arrive at mixed results. We find that the ECI and the core CPI (which excludes the often volatile food and energy components) frequently move in tandem, with only a slight tendency for labor cost developments to precede price movements (Chart 1).

These mixed findings suggest that a disaggregated approach to explaining CPI inflation would be fruitful. We break down the CPI into various components in

\section{Chart 1 \\ Labor Costs and Core Inflation \\ Four-Quarter Changes}

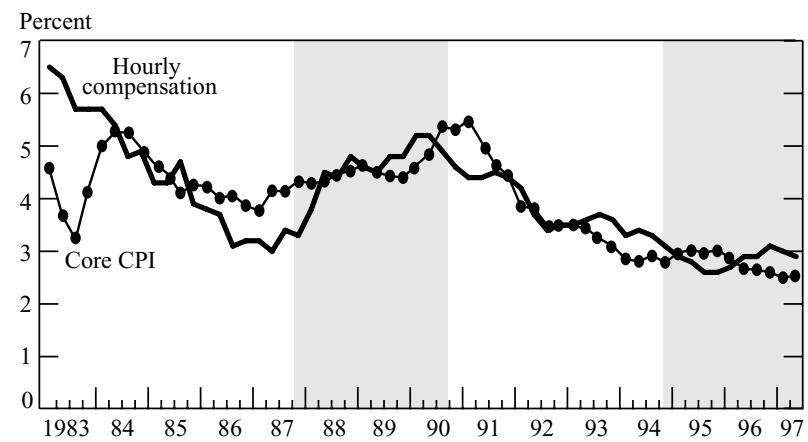

Sources: U.S. Department of Labor, Bureau of Labor Statistics; author's calculations.

Notes: Hourly compensation is based on the employment cost index for total compensation among private industry workers. The core consumer price index excludes food and energy. The shaded areas represent periods in which the unemployment rate was below 6 percent. order to isolate those goods or services whose prices are most likely to respond to changes in labor costs. In theory, one would expect labor costs to have the strongest direct impact on prices when these costs represent a substantial portion of the cost of production and when producers have some control over the setting of prices. Thus, we look for categories of goods or services that meet both of these criteria.

\section{We break down the CPI into various components in order to isolate those goods or services whose prices are most likely to respond to changes in labor costs.}

We find that factors other than labor costs dominate price determination for many of the CPI's components. In fact, these components (identified as "other expenditure categories" in the table on p. 3) represent a significant share of consumer spending. For example, prices of energy and food eaten at home, which together make up about 17 percent of the CPI, often fluctuate because of weather conditions, international political developments, or other temporary factors unrelated to producers' labor costs. Housing costs, which account for about 26 percent of the CPI, are also little affected by current labor costs, because the shortrun supply of housing is essentially fixed, with rents determined much more by land values and the cost of materials than by the labor input into current housing services. ${ }^{2}$ Moreover, in the case of several components of the CPI, the government plays a major role in setting prices, so even if labor costs were an important part of production we would not expect them to affect prices directly. Among these components are utilities, public transportation, and medical care-services in which the government frequently either regulates prices or provides the services itself - and alcoholic beverages and tobacco, whose price movements often reflect shifts in federal or state taxation.

For the purpose of our analysis, the rest of consumer spending can be divided into two classes: one in which product prices are determined through global markets and one in which price determination is much more local. In the goods sector, the presence of global competition arguably limits firms' ability to raise product prices in response to higher labor costs. This effect is strongest in industries that have high and rising import-penetration ratios (apparel is a prominent example), because imports lead directly to lower prices. Even in other goods-producing industries, how- 
ever, the threat of competition from low-cost producers-foreign or domestic-can act to restrain price increases. Some firms respond to higher labor costs by taking steps aimed at boosting productivity growth, thus avoiding the need to raise prices in order to maintain profitability. Firms that cannot either raise prices or increase productivity will suffer reduced profits. Therefore, for most goods we would expect labor costs to have only a limited direct impact on prices.

In the services sector, however, providers of consumer services typically are much less subject to global competition than goods producers are, such that any cost increase can be more easily passed on to consumers. For example, convenience based on location is an essential feature of the dry-cleaning industry in New York City. The existence of lower cost producers of the same service in other cities will therefore have no bearing on the price-setting mechanism for this service in New York City. Barring the entry of lower cost providers into the same neighborhood, we would thus expect any local increase in wages to lead quickly to higher prices. Moreover, the ability of service providers to improve productivity in response to higher labor costs (at least in ways that can be measured) appears to be considerably more limited than it is for goods producers: Because many services are based on direct interaction with customers, any increase in the number of customers served per hour may diminish service quality.

Taking these descriptions of the goods and services sectors into account, we have decomposed the CPI into three broad groups. The table below lists the components of these groups, together with their December 1995 "relative importances"- a BLS term that is roughly equivalent to expenditure shares. ${ }^{3}$ The first group, "labor-cost-sensitive services," is one in which labor costs are important and prices are set primarily in local markets. It consists of food away from home and a variety of other services. The second group, "labor-cost-sensitive goods," is one in which labor costs may be important but price determination is global, such as motor vehicles, clothing, and a number of other goods. The third group, described earlier, consists of all other expenditure categories, including food at home, energy, and housing. The rest of this article will examine the first two groups, which together account for about 40 percent of consumer expenditures.

\section{Testing the Compensation-Price Links}

To test our hypothesis that the effect of any acceleration in labor costs on inflation is concentrated in the services sector, we calculate quarterly estimates of the CPI for the two groups beginning in 1983 (Chart 2).

\section{CPI Expenditure Categories}

\begin{tabular}{|c|c|c|c|c|c|}
\hline \multicolumn{2}{|c|}{ Labor-Cost-Sensitive Services } & \multicolumn{2}{|c|}{ Labor-Cost-Sensitive Goods } & \multicolumn{2}{|c|}{ Other Expenditure Categories } \\
\hline Category & $\begin{array}{c}\text { Relative } \\
\text { Importance }^{\text {a }}\end{array}$ & Category & $\begin{array}{c}\text { Relative } \\
\text { Importance }^{\mathrm{a}}\end{array}$ & Category & $\begin{array}{c}\text { Relative } \\
\text { Importance }\end{array}$ \\
\hline Food away from home & 5.9 & New vehicles & 5.0 & Homeowners' costs & 20.1 \\
\hline Personal and educational services & 4.1 & Apparel commodities & 5.0 & Food at home & 9.9 \\
\hline Other private transportation services ${ }^{\mathrm{b}}$ & 4.0 & House furnishings & 3.4 & Medical care & 7.4 \\
\hline Entertainment services & 2.4 & Entertainment commodities & 2.0 & Rent, residential & 5.8 \\
\hline Other renters' costs ${ }^{\mathrm{c}}$ & 2.2 & Used cars & 1.3 & Fuels & 3.8 \\
\hline $\begin{array}{l}\text { Private transportation: } \\
\text { maintenance and repairs }\end{array}$ & 1.5 & $\begin{array}{l}\text { Housekeeping supplies } \\
\text { Toilet goods and }\end{array}$ & 1.1 & $\begin{array}{l}\text { Other utilities and } \\
\text { public services }^{\mathrm{e}}\end{array}$ & 3.2 \\
\hline Housekeeping services & 1.5 & personal care appliances & 0.6 & Motor fuel & 2.9 \\
\hline Personal care services & 0.6 & $\begin{array}{l}\text { Other private } \\
\text { transportation commodities }\end{array}$ & 0.6 & $\begin{array}{l}\text { Tobacco and smoking } \\
\text { products }\end{array}$ & 1.6 \\
\hline Shelter: maintenance and & 0.0 & School books and supplies & 0.3 & Alcoholic beverages & 1.6 \\
\hline repair services & 0.1 & $\begin{array}{l}\text { Shelter: maintenance and } \\
\text { repair commodities }\end{array}$ & 0.1 & Public transportation & 1.5 \\
\hline Total & 22.8 & Total & 19.4 & Total & 57.7 \\
\hline
\end{tabular}

Sources: Names of categories and estimates of relative importance are drawn from the U.S. Department of Labor, Bureau of Labor Statistics. The division of the BLS categories into "labor-cost-sensitive services," "labor-cost-sensitive goods," and "other expenditure categories" is based on the author's evaluation of the responsiveness of various types of expenditures to wage changes.

${ }^{a}$ The BLS defines relative importance as the share of total expenditures for which a category would account given current prices and a level of consumption unchanged from the base period 1982-84. The figures reported in the table are based on 1995 prices.

${ }^{\mathrm{b}}$ Includes auto insurance, finance charges, and fees.

'Includes out-of-town lodging, lodging at school, and tenants' insurance.

dIncludes auto parts, products, and equipment.

${ }^{\mathrm{e}}$ Includes telephone, cable television, water, and trash collection services. 
The estimates are constructed by taking averages of the indexes for the individual components, with the averages weighted by the relative importance of the components. Overall, we find that service prices throughout this period have risen relative to goods prices. Using our decomposed CPI and data from the sectorspecific ECI, we now examine the link from compensation to prices in the goods-producing and serviceproducing sectors separately.

In the goods sector, increases in the rate of compensation growth do not appear to lead increases in price inflation (Chart 3). Most notably, the uptick in the CPI in 1986-87 preceded the acceleration in compensation growth, and in both 1989 and 1996 the CPI and the ECI moved in opposite directions. This result is confirmed by regression tests estimated over the fourth quarter of 1983 through the fourth quarter of 1996 using seasonally adjusted data. These tests indicate that past changes in the ECI for goods-producing industries do not improve on forecasts of changes in the CPI for labor-cost-sensitive goods-an unsurprising result given the limited ability of many goods producers in highly competitive markets to raise prices in response to higher costs. ${ }^{4}$

A rather different picture emerges in the services sector (Chart 4). We see that both the acceleration in labor costs during the late 1980s and the deceleration beginning in 1990 preceded similar movements in the CPI for labor-cost-sensitive services and that both the CPI and the ECI have been quite stable since 1993. Running the same regression tests conducted for the

\section{Chart 2}

\section{Price Inflation in Major Expenditure Categories}

Four-Quarter Changes

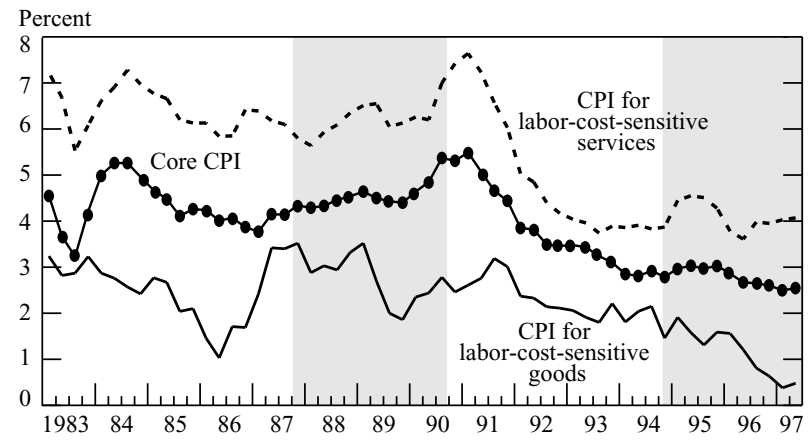

Sources: U.S. Department of Labor, Bureau of Labor Statistics; author's calculations

Note: The shaded areas represent periods in which the unemployment rate was below 6 percent. goods sector, we are unable to reject the hypothesis that changes in the ECI for service-producing industries help predict changes in the CPI for labor-costsensitive services. ${ }^{5}$ Over a three-quarter period, the estimated cumulative impact of hourly labor costs on the inflation rate is about 0.4 percentage point for each percentage point change in the labor cost inflation rate. ${ }^{6}$ Because labor-cost-sensitive services represent nearly 23 percent of the CPI (see table), this result

\section{In the goods sector, increases in the rate of compensation growth do not appear to lead increases in price inflation.}

implies that such an increase in labor costs directly adds about 0.1 point to overall inflation $(0.4 * 0.23)$. This finding is consistent with the view that providers of services have a greater ability than goods producers to pass on higher costs to their customers.

We conduct additional regression tests to determine whether accelerating labor costs in the services sector can increase inflation indirectly, through their effects on the price of consumer goods. Current services, after all, play a role in the production and distribution of consumer goods. For example, if manufacturers are forced to pay more for financial and legal services, or for the shipping of goods from factories to stores, then these increases are likely to be reflected in the price

\section{Chart 3}

\section{Compensation and Price Inflation: Goods}

Four-Quarter Changes

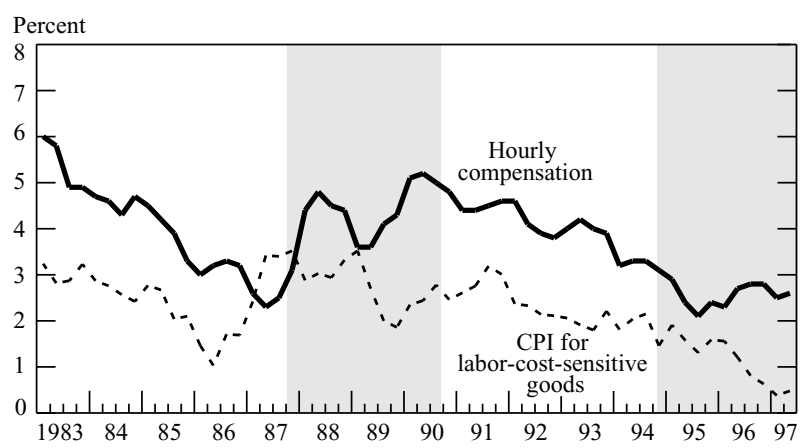

Sources: U.S. Department of Labor, Bureau of Labor Statistics; author's calculations.

Notes: Hourly compensation is based on the employment cost index for total compensation among private industry workers in the goods-producing industries. The shaded areas represent periods in which the unemployment rate was below 6 percent. 


\section{Chart 4 Compensation and Price Inflation: Services \\ Four-Quarter Changes}

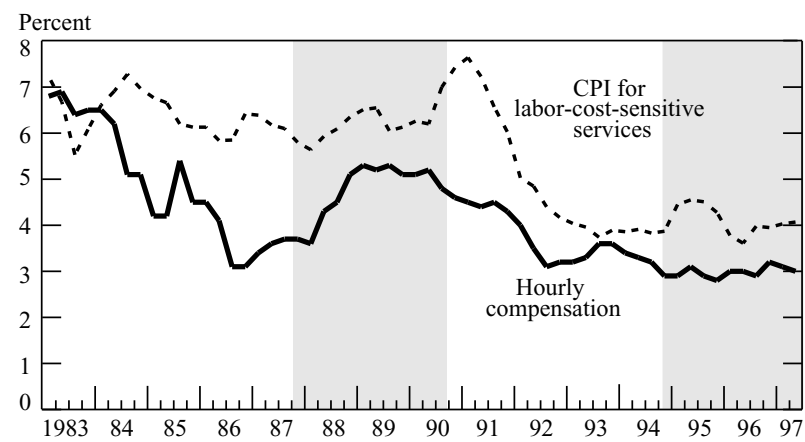

Sources: U.S. Department of Labor, Bureau of Labor Statistics; author's calculations.

Notes: Hourly compensation is based on the employment cost index for total compensation among private industry workers in the service-producing industries. The shaded areas represent periods in which the unemployment rate was below 6 percent.

of the goods. Although a full simulation of the impact of any increase in labor costs is beyond the scope of this article, our tests of this indirect influence indicate that each percentage point increase in the inflation rate for labor-cost-sensitive services adds roughly 0.4 percentage point to inflation in the other components of the CPI. ${ }^{7}$ This finding implies that in addition to labor costs' direct effect on inflation, the original percentage point increase in labor costs has an indirect impact on overall inflation of about 0.1 point $(0.4 * 0.4 * 0.77)$. When we test the effect of a price change in labor-costsensitive goods on the price of labor-cost-sensitive ser-

\section{We find that if compensation growth accelerates in the service-producing sector, that growth is likely to show up directly as more rapid inflation in service prices.}

vices, however, we find no evidence of a link, most likely because newly purchased goods play a fairly minor role in the provision of services.

Although our results suggest that rising labor costs can increase inflation both directly and indirectly, we are careful to note that other kinds of supply shocks can trigger an inflationary spiral. For instance, a large and sustained increase in food or energy price inflation can cause workers to increase their wage demands, a development that could in turn force up prices of other items through the mechanisms discussed above. However, even in these cases, services sector labor costs are likely to be an important part of the inflationary transmission mechanism.

\section{Conclusion}

The results presented here confirm a link from services sector wages and prices to overall inflation. We find that if compensation growth accelerates in the serviceproducing sector, that growth is likely to show up directly as more rapid inflation in service prices. Moreover, higher hourly labor costs in services can, through their contribution to the production and distribution of goods, indirectly affect goods prices. Given earlier researchers' findings showing a link from prices to wages, even these modest initial effects may therefore be enough to set off an inflationary spiral. Since no such effects are found to arise from an acceleration of labor cost increases in the goods-producing sector, policymakers seeking to prevent a resurgence of inflation may wish to pay particular attention to hourly labor costs in the service-producing private sector.

\section{Notes}

1. The main advantage of the ECI over two other common compensation measures - the monthly average hourly earnings series (which excludes benefits) and the nonfarm business sector compensation measure - is that it controls for the impact of shifts in the mix of jobs by measuring wages and benefits for a fixed set of industries and occupations. It is also designed to remove the influence of changes in the volume of overtime worked on reported hourly compensation. One disadvantage of the ECI is that it does not adjust for changes in productivity growth; however, a related measure - unit labor costs - which does control for productivity changes, cannot be reliably decomposed into goods and services.

2. Over time, however, rents are influenced by general wage increases in the sense that the resulting higher consumer incomes boost the demand for housing.

In the CPI, the cost of owner-occupied housing is expressed in terms of "owners' equivalent rent," meaning the imputed value of the services provided by the housing unit. In practice, the estimation of owners' equivalent rent is largely based on observed rents paid for comparable housing units in similar locations.

3. To be precise, the BLS (U.S. Department of Labor 1997, p. 170) defines a category's relative importance as the "share of total expenditures" for which the category would account "if quantities consumed were unaffected by changes in relative prices and actually remained constant [at the fixed 1982-84 weight]." Thus, over time, relative importance increases for categories in which prices are rising faster than the overall CPI and decreases for categories in which relative prices are falling. In 
January 1998, the BLS plans to introduce updated weights reflecting 1993-95 spending patterns.

4. Specifically, we performed Granger-causality tests in which the seasonally adjusted change in the CPI for each quarter was regressed on lagged values for the quarterly change in the ECI, as well as its own lagged values, and then conducted an F-test for joint significance of the lagged ECI variables. In the case of goods using three lags, the F-statistic on the lagged ECI variables was .69 , with a significance level of 56.4 percent. Tests using different numbers of lags yielded similar results.

5. For three lags, the F-statistic was 6.31, with a significance level of 0.1 percent.

6. The standard error of this estimate is 0.17 percentage point.

7. For two lags, the F-statistic for a link from labor-cost-sensitive services to labor-cost-sensitive goods was 4.98 (significance level 1.09 percent), with a .34 point cumulative impact (standard error .14). In the case of a link from services to all other items, the F-statistic was 5.42 (significance level .75 percent), with a cumulative impact of .40 point (standard error .22).

\section{References}

Emery, Kenneth M., and Chih-Ping Chang. 1996. "Do Wages Help Predict Inflation?" Federal Reserve Bank of Dallas Economic Review, first quarter: 2-9.

Gordon, Robert J. 1988. "The Role of Wages in the Inflation Process." American Economic Review 78, no. 2 (May): 276-83.

Huh, Chan G., and Bharat Trehan. 1995. "Modeling the TimeSeries Behavior of the Aggregate Wage Rate." Federal Reserve Bank of San Francisco Economic Review, no. 1: 3-13.

Lown, Cara S., and Robert W. Rich. 1997. "Is There an Inflation Puzzle?" Federal Reserve Bank of New York Research Paper no. 9723

Mehra, Yash. 1991. "Wage Growth and the Inflation Process: An Empirical Note." American Economic Review 81, no. 4 (September): 931-7.

1993. "Unit Labor Costs and the Price Level." Federal Reserve Bank of Richmond Economic Review 79, no. 4: 35-52.

U.S. Department of Labor. Bureau of Labor Statistics. 1997. BLS Handbook of Methods.

\section{About the Author}

David A. Brauer is an economist in the Domestic Research Function of the Research and Market Analysis Group.

The views expressed in this article are those of the author and do not necessarily reflect the position of the Federal Reserve Bank of New York or the Federal Reserve System.

Current Issues in Economics and Finance is published by the Research and Market Analysis Group of the Federal Reserve Bank of New York. Dorothy Meadow Sobol is the editor.

Editorial Staff: Valerie LaPorte, Mike De Mott, Elizabeth Miranda

Production: Graphics and Publications Staff

Subscriptions to Current Issues are free. Write to the Public Information Department, Federal Reserve Bank of New York, 33 Liberty Street, New York, N.Y. 10045-0001, or call 212-720-6134. Back issues are also available.

Interested readers are encouraged to visit our web site (www.ny.frb.org/rmaghome), where you can view, download, and print any article in Current Issues in Economics and Finance or in our flagship publication, the Economic Policy Review, as well as certain issues of Staff Reports. You can also view abstracts for Staff Reports and Research Papers and order the full-length, hard-copy version of any paper in these technical series electronically. 